

\section{Problem/research questions}

-High rainfall spatial variability in Pacific Islands

-Mean annual rainfall ranges 200 to $10,000 \mathrm{~mm}$ over the Hawaiian Islands (Giambelluca et al, 2013)

-Decrease in number of rain gauging stations

-Can we use rainfall data from neighboring watersheds for ungauged watersheds in spatially heterogeneous rainfall patterns?

- How do rainfall data scarcity affect watershed model performance compared to relatively well gauged watersheds? 


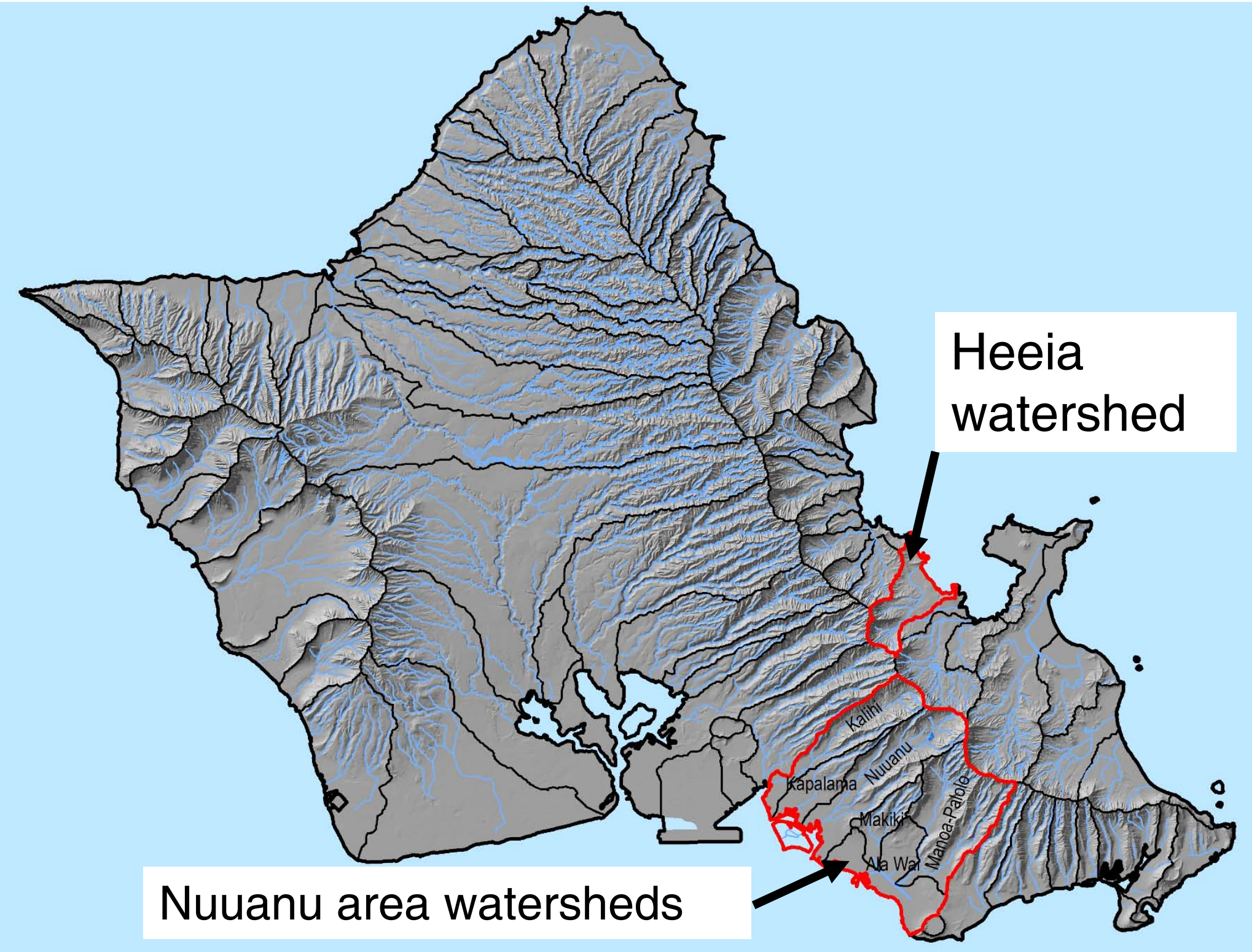

-Small scale watersheds with unique hydrological features, soil types, topography, \& highly variable climate conditions. 


\section{Study area (American Samoa)}

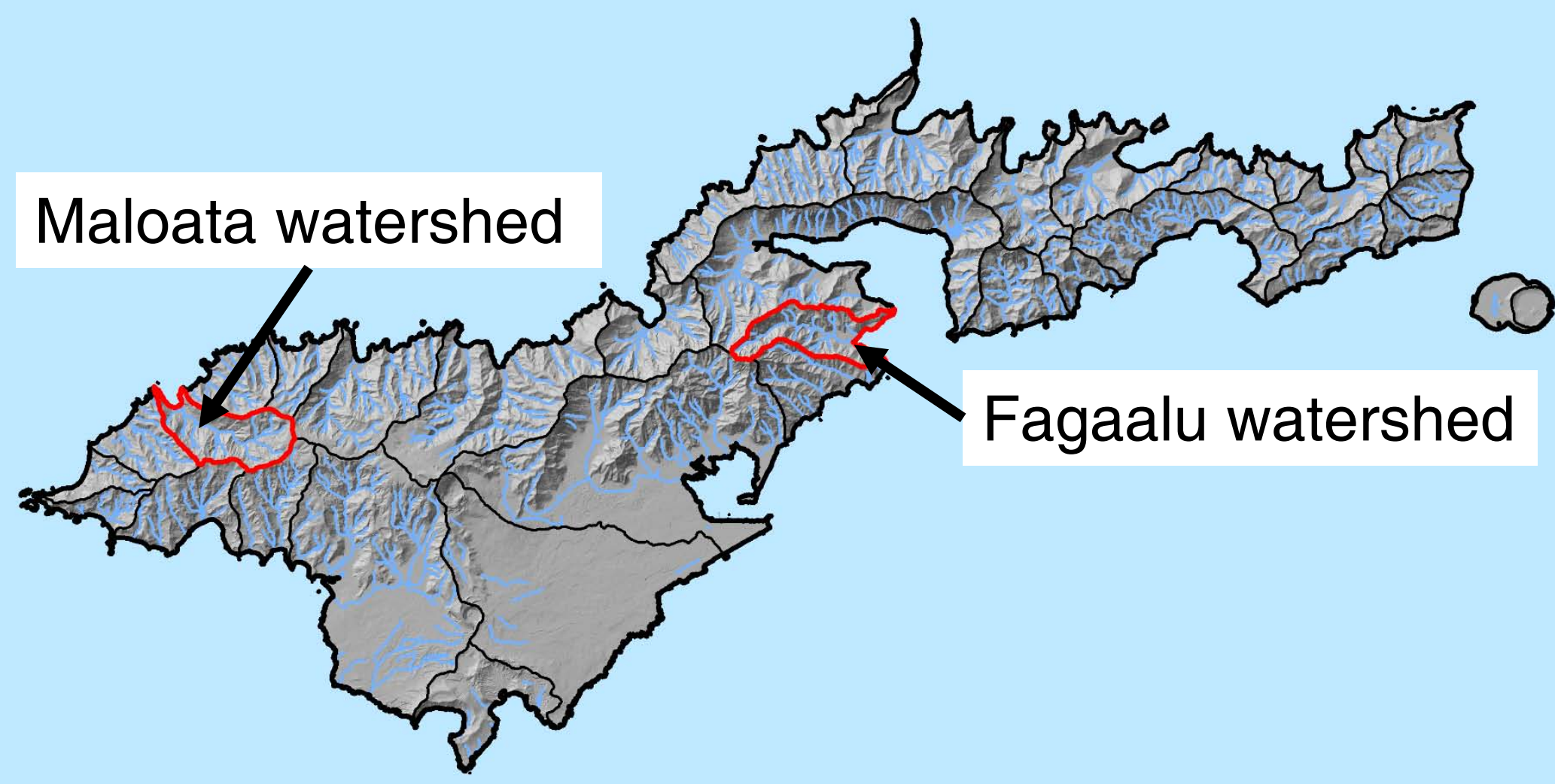

-Small scale watersheds with unique hydrological features, soil types, topography, \& highly variable climate conditions. 


\section{Objectives}

-To develop watershed model for:

$>$ Heeia watershed: environmental twist

$>$ Nuuanu watershed: water conservation twist

$>$ Fagaalu watershed: environmental twist

- To assess the effect of rainfall input on watershed model performance in spatially heterogeneous watersheds 


\section{Approach}

Utilize the model Soil and Water Assessment Tool (SWAT)

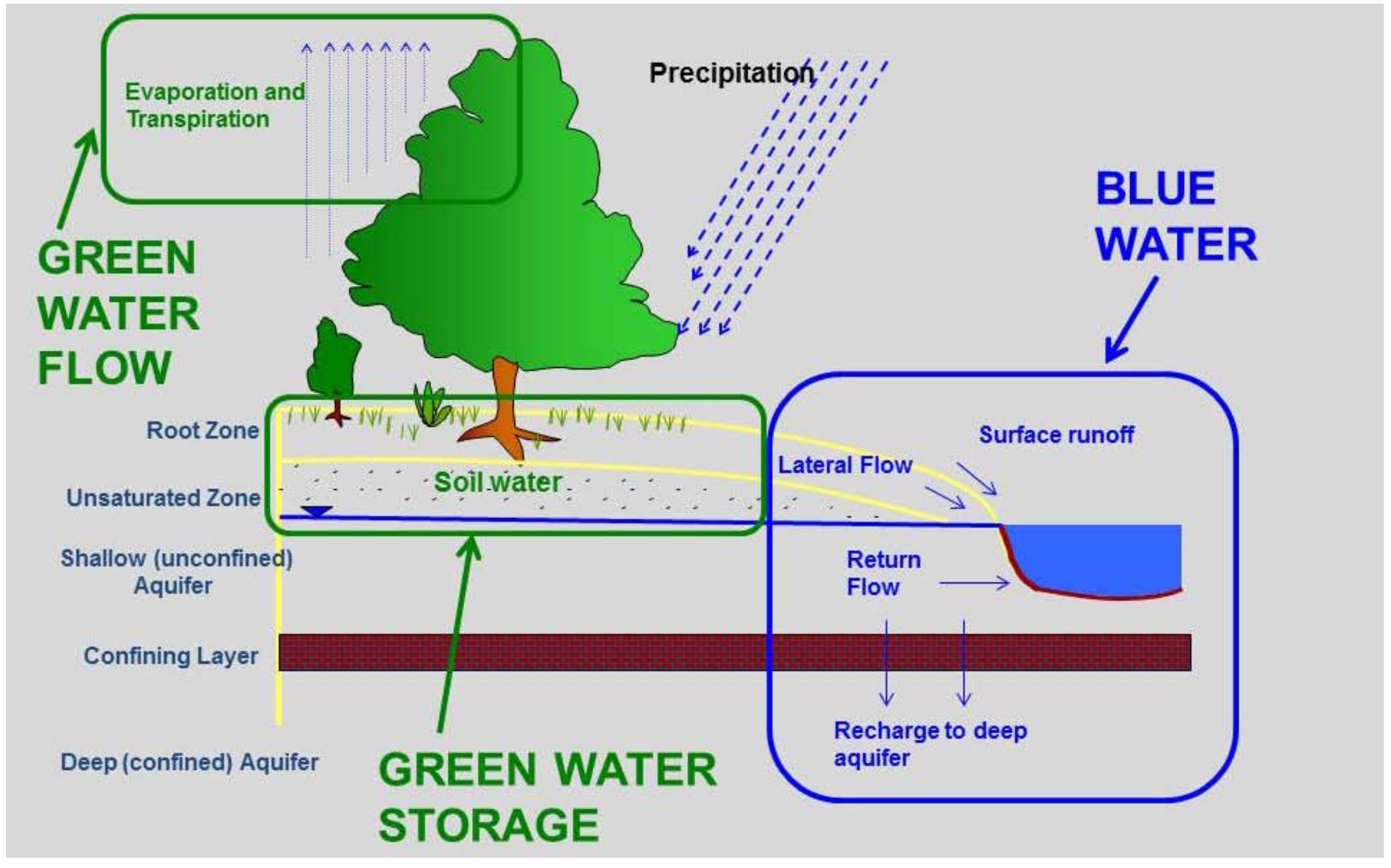

Soil-water-plant interaction processes and water balance 


\section{SWAT modeling approach}

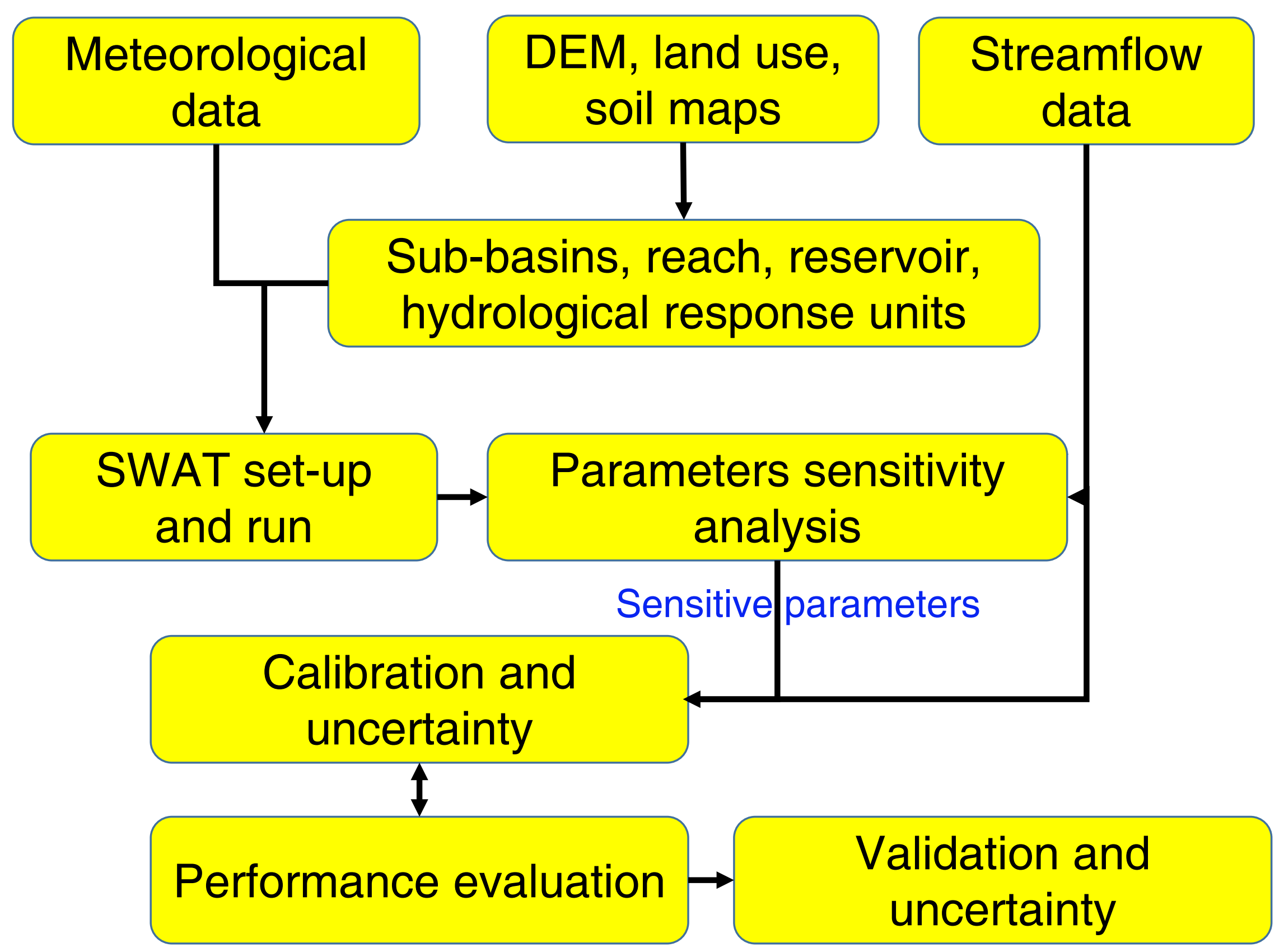




\section{Hydro-meteorological (Oahu watersheds)}

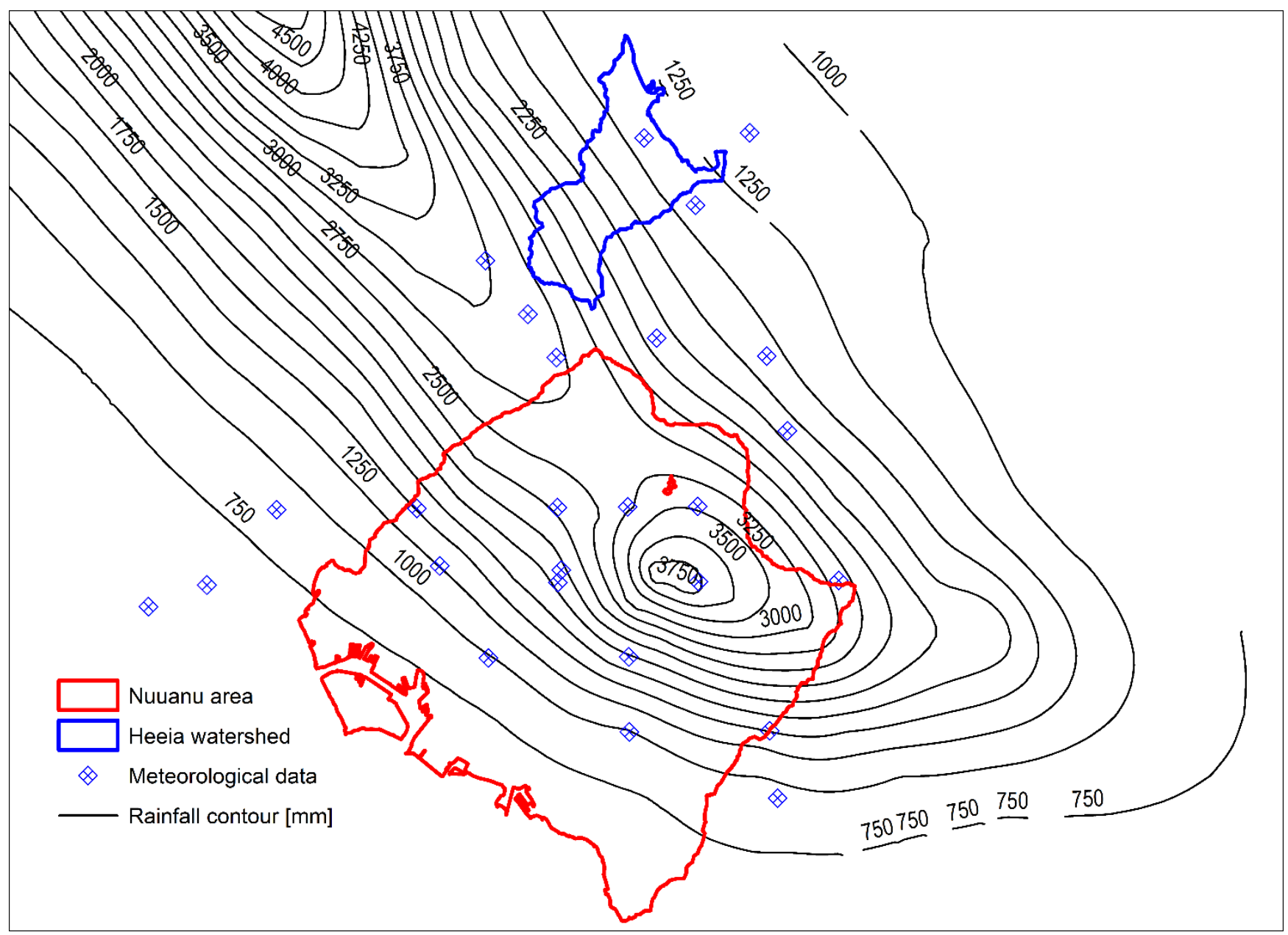

- Missing values: filled based on contour maps, nearby stations, correlation and interpolation techniques for ungauged sites 


\section{Hydro-meteorological (Fagaalu)}

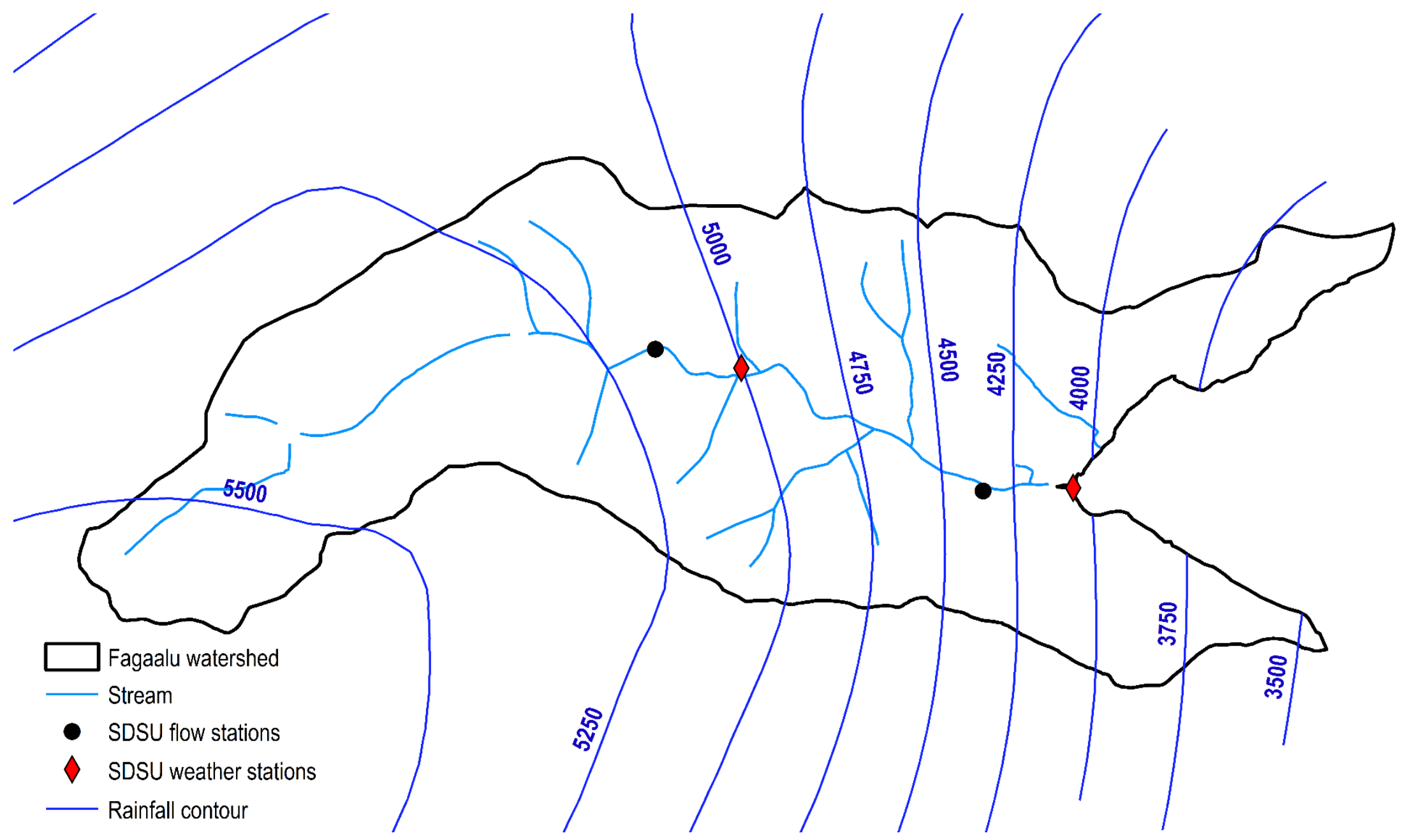

- Missing values: filled based on contour maps, nearby stations, correlation and interpolation techniques for ungauged sites 


\section{Data and SWAT development Heeia watershed}

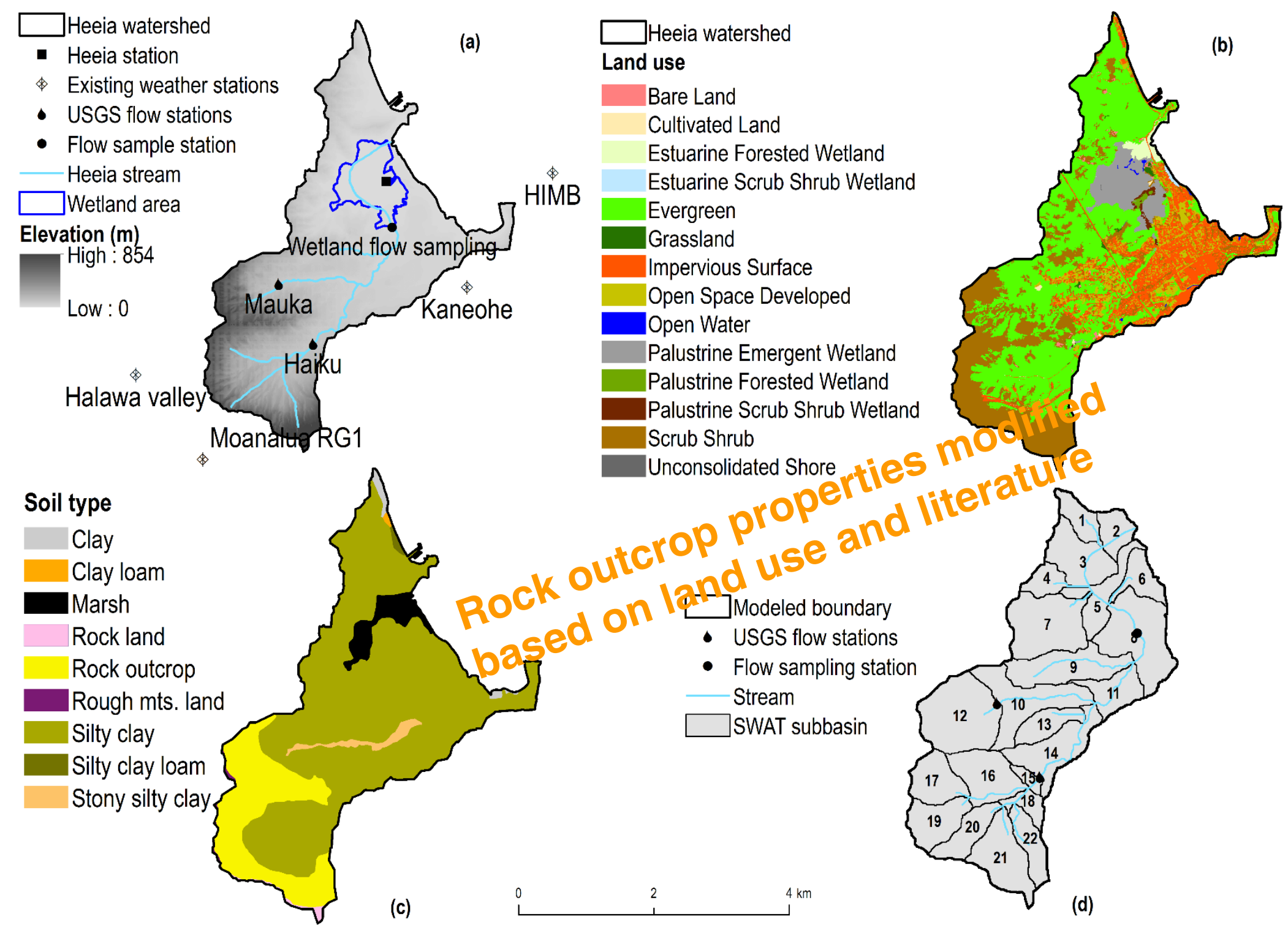




\section{Data and SWAT development for Nuuanu area}

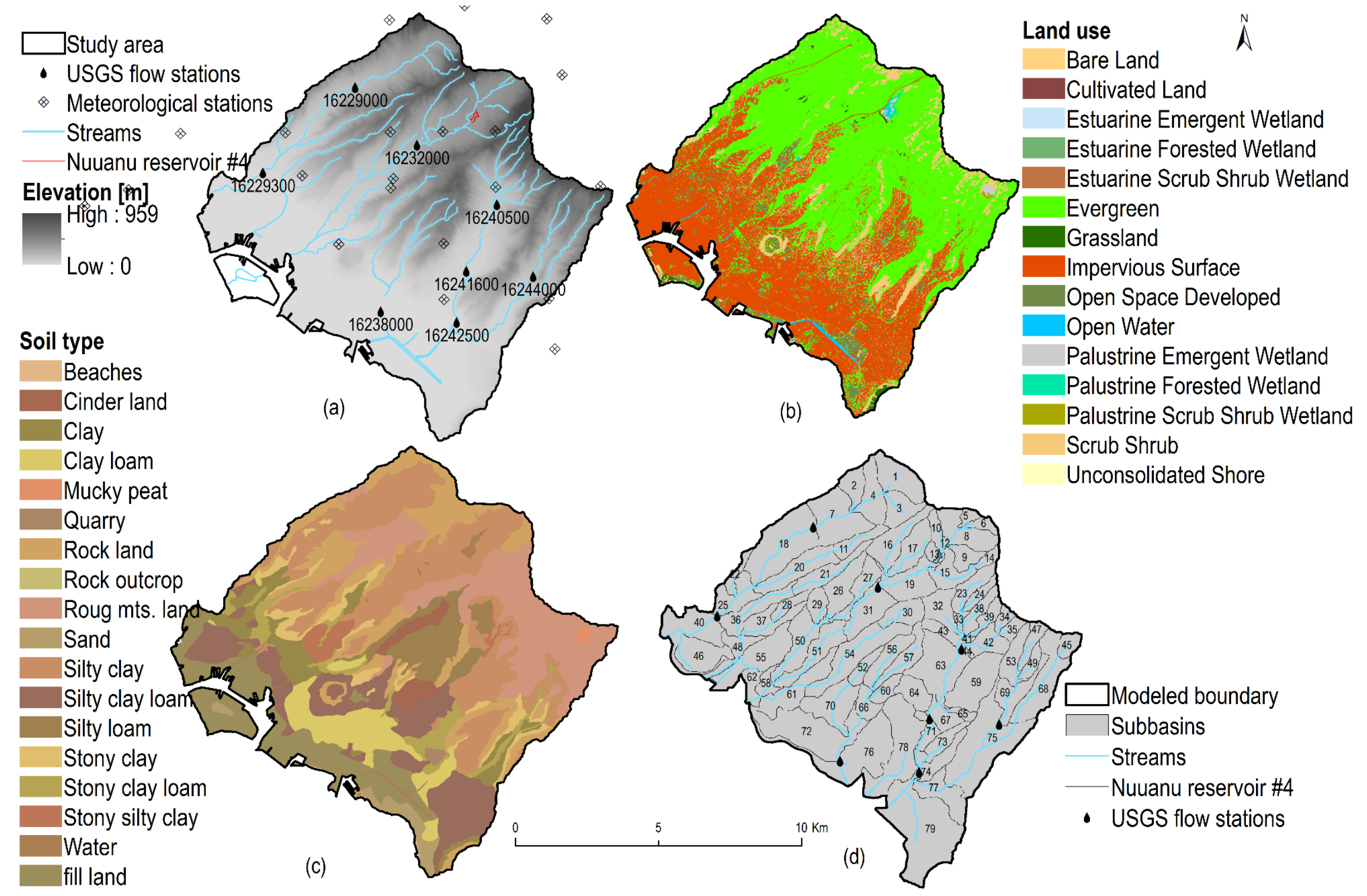




\section{Data and SWAT development for Fagaalu}

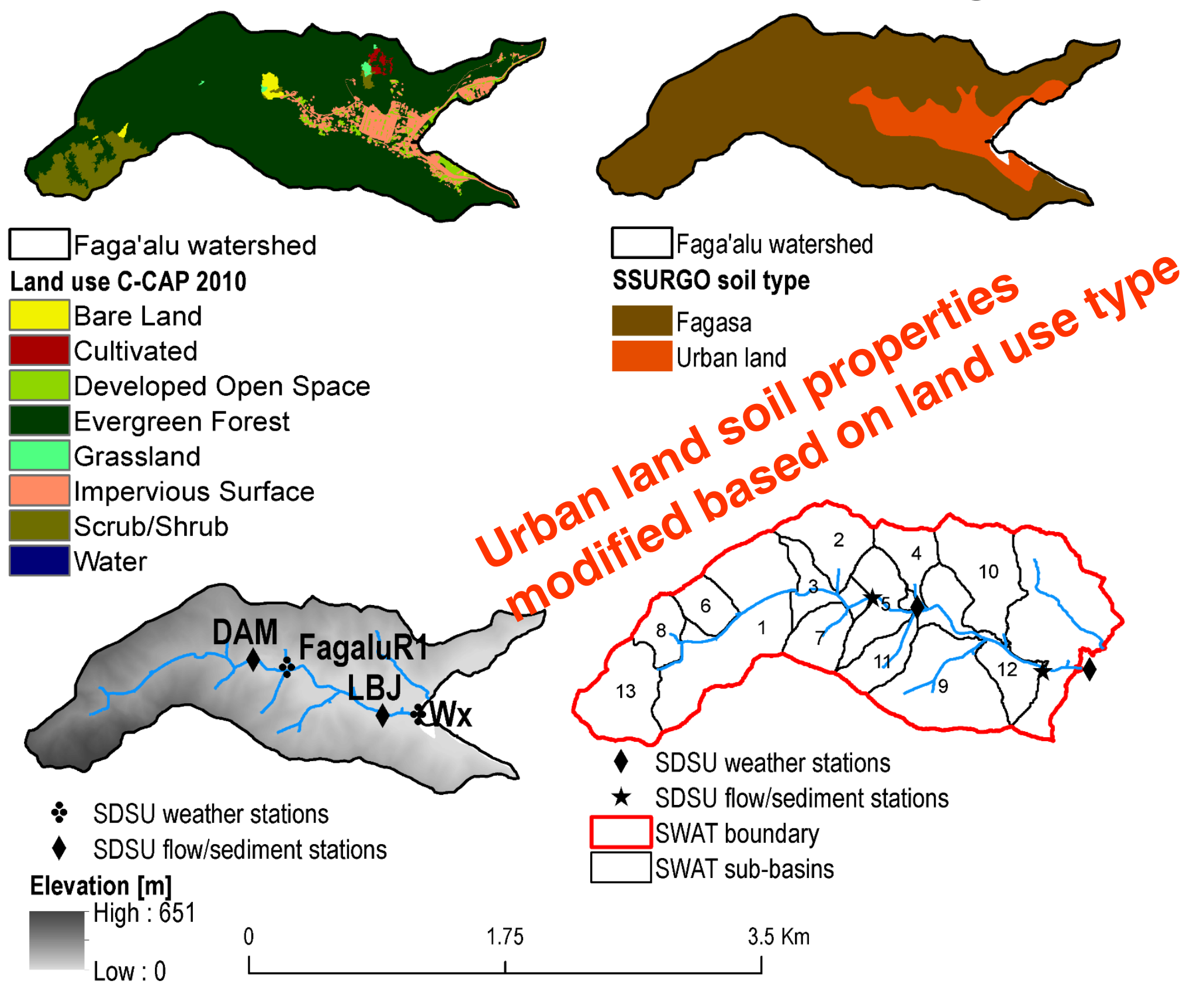




\section{Data and SWAT development for Maloata}
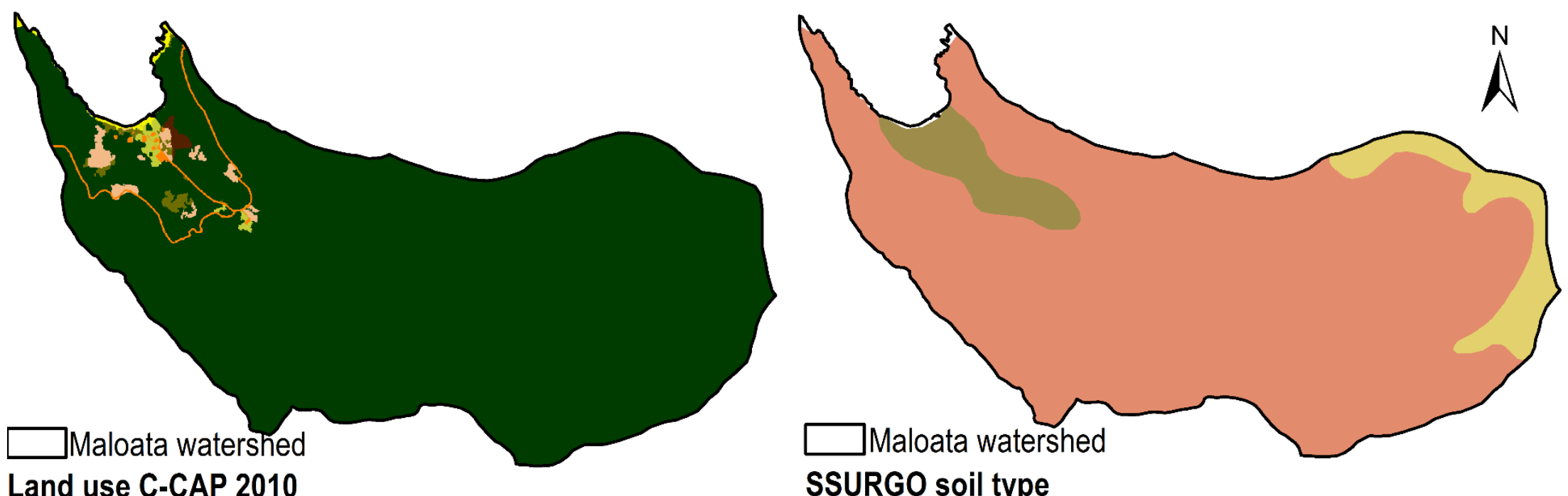

Land use C-CAP 2010

Bare Land

Cultivated

Developed Open Space

Evergreen Forest Grassland

All climatic data de

Aua

Fagasa Impervious Surface Scrub/Shrub watersheds Water

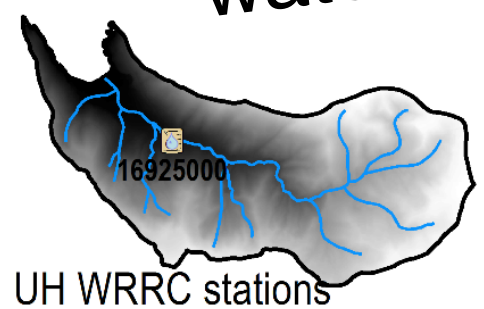

$$
\begin{aligned}
& \text { UH WRRC stations } \\
& \text { NCDC stations } \\
& \text { USGS flow station }
\end{aligned}
$$

Elevation [m]

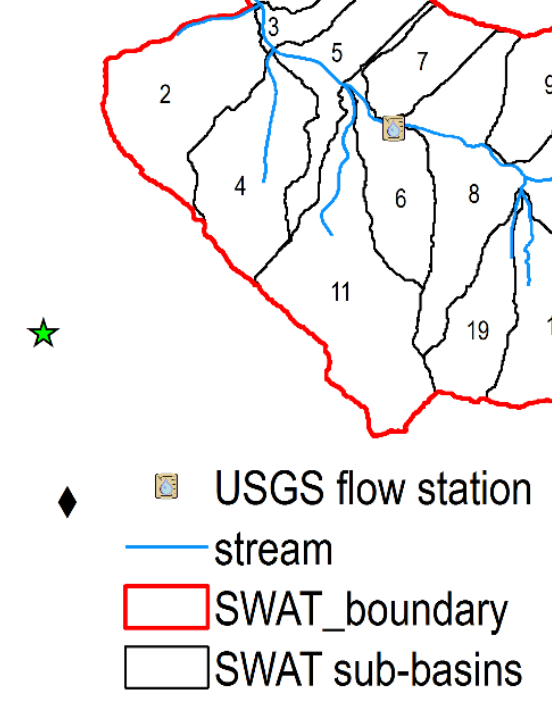




\section{Sensitive parameters for Oahu}

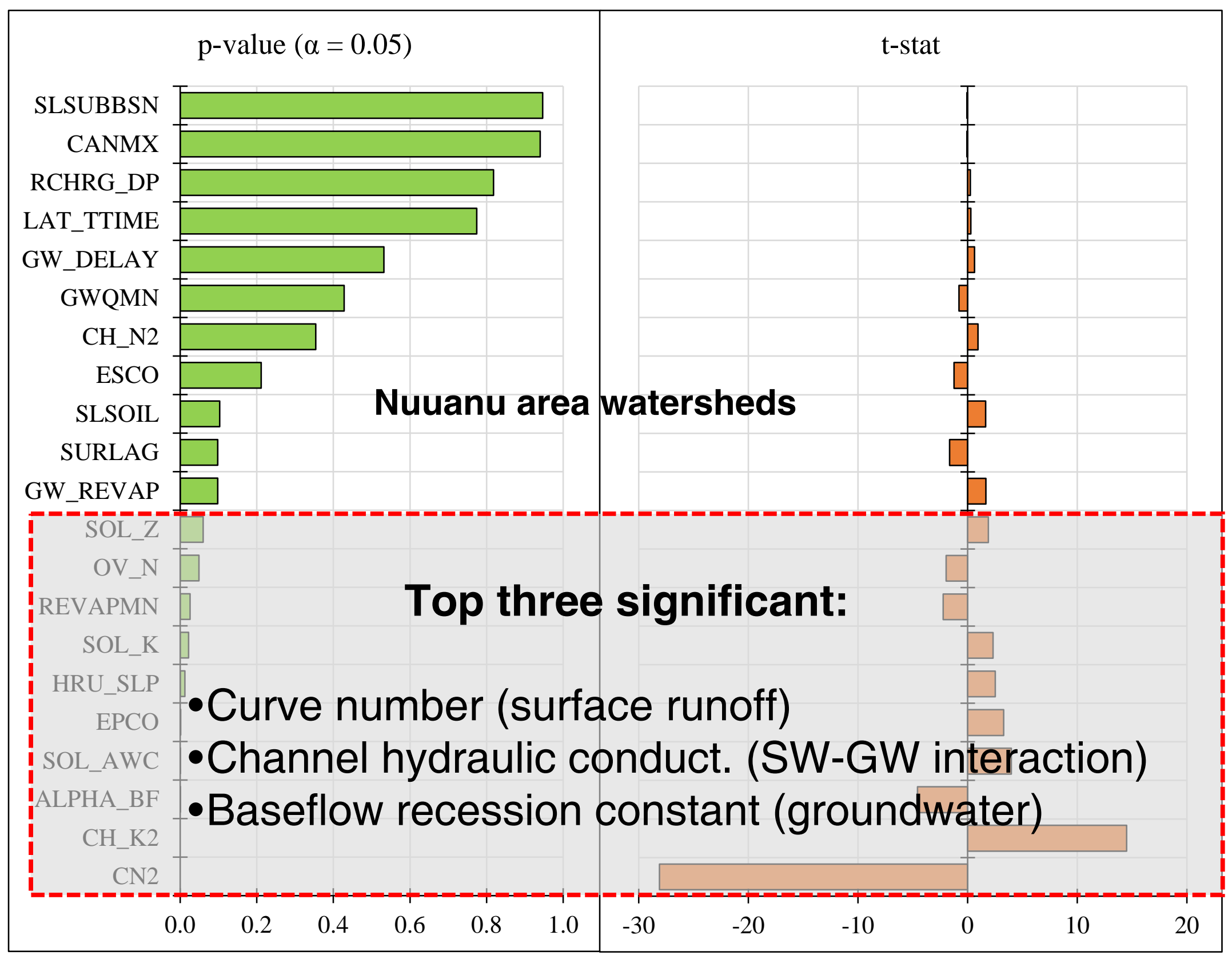




\section{Sensitive parameters for American Samoa}

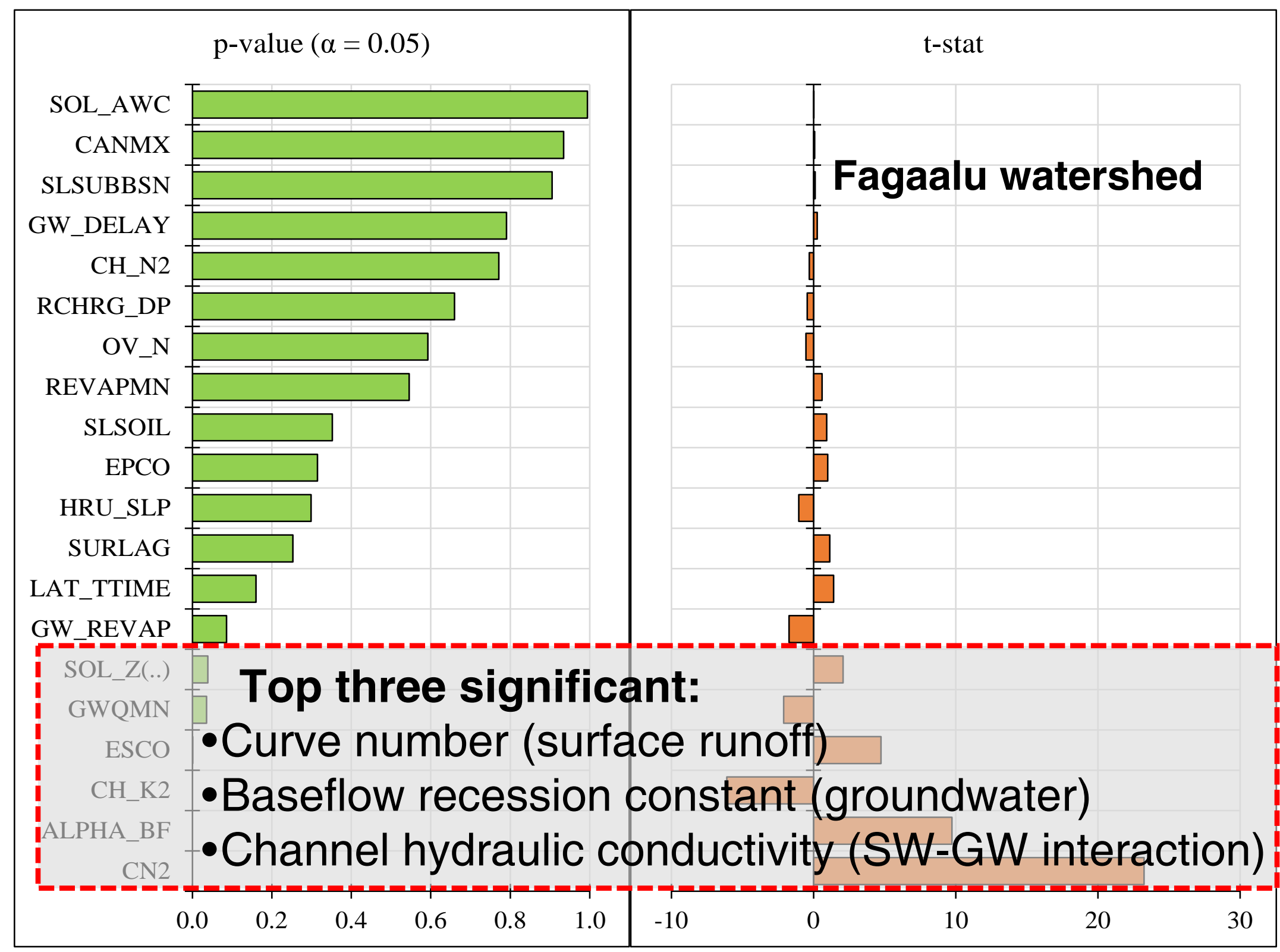

- Top 3 sensitive parameters are the same for Oahu and Am Samoa 


\section{Calibrated SWAT parameter values}
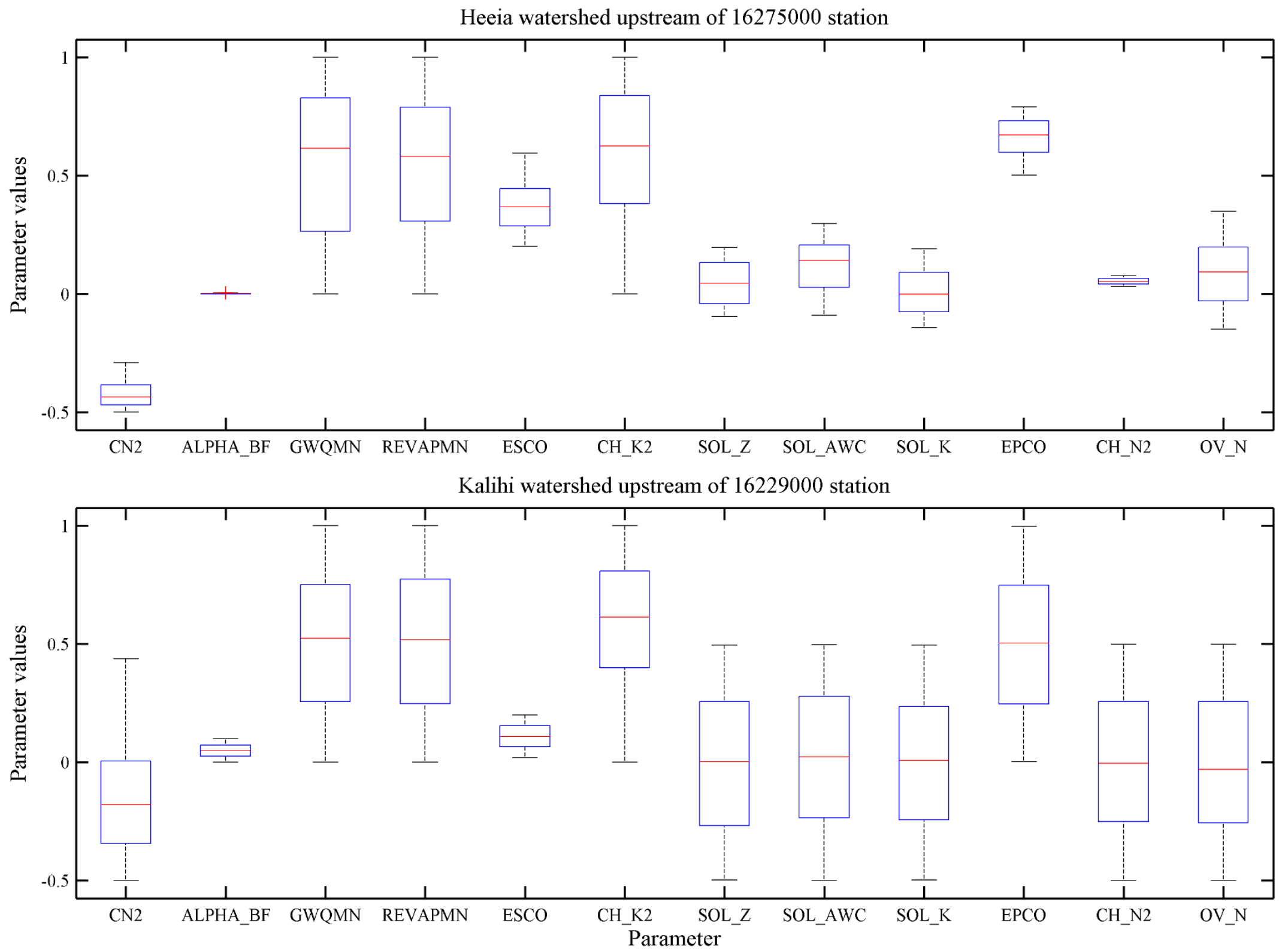

- Good solutions (NSE $\geq 0.2$, Heeia, $\geq 0.5$, Kalihi) parameter values 
Observed streamflow well represented with rain records
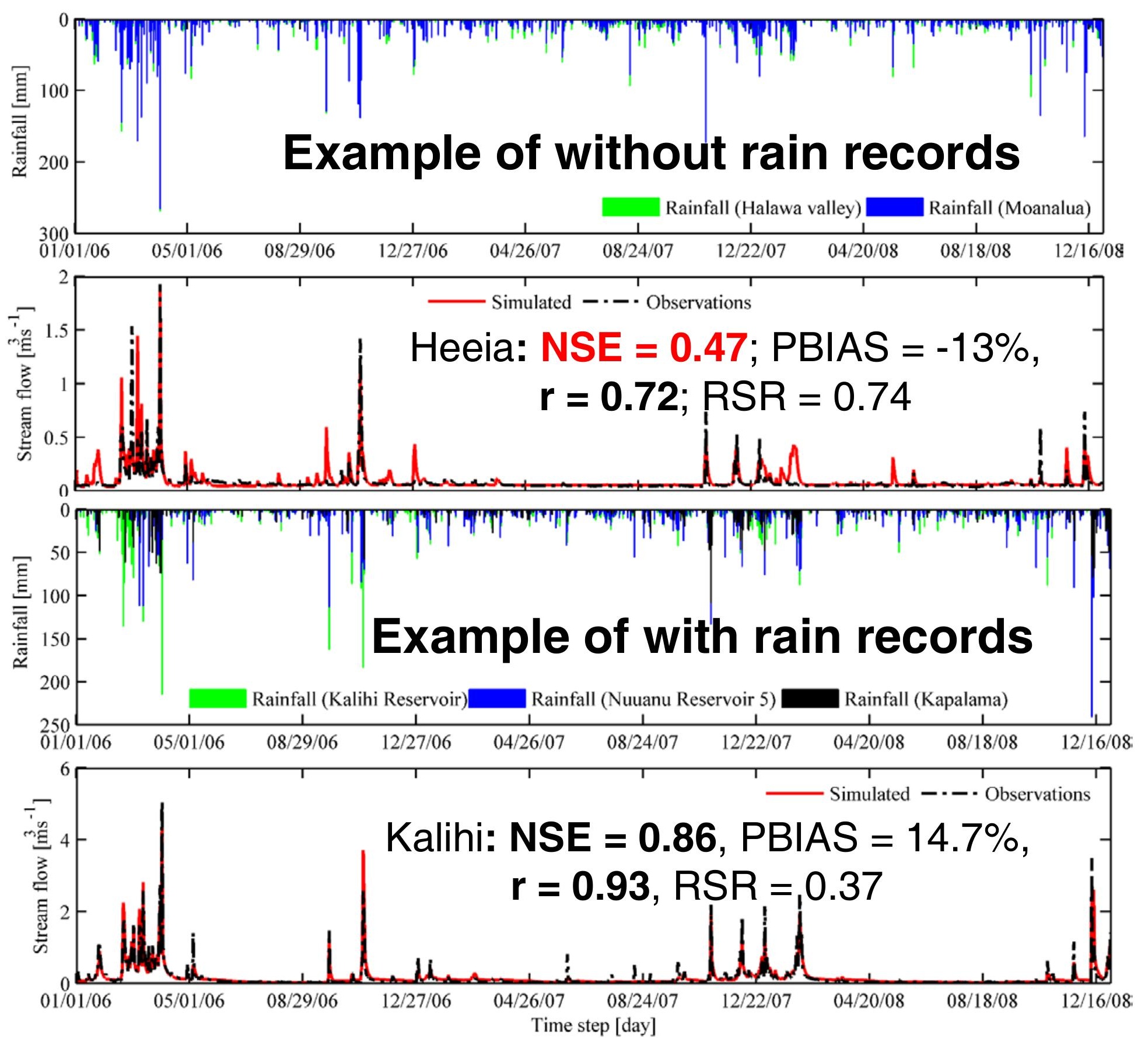


\section{Use of rainfall data within watershed improves SWAT model performance}
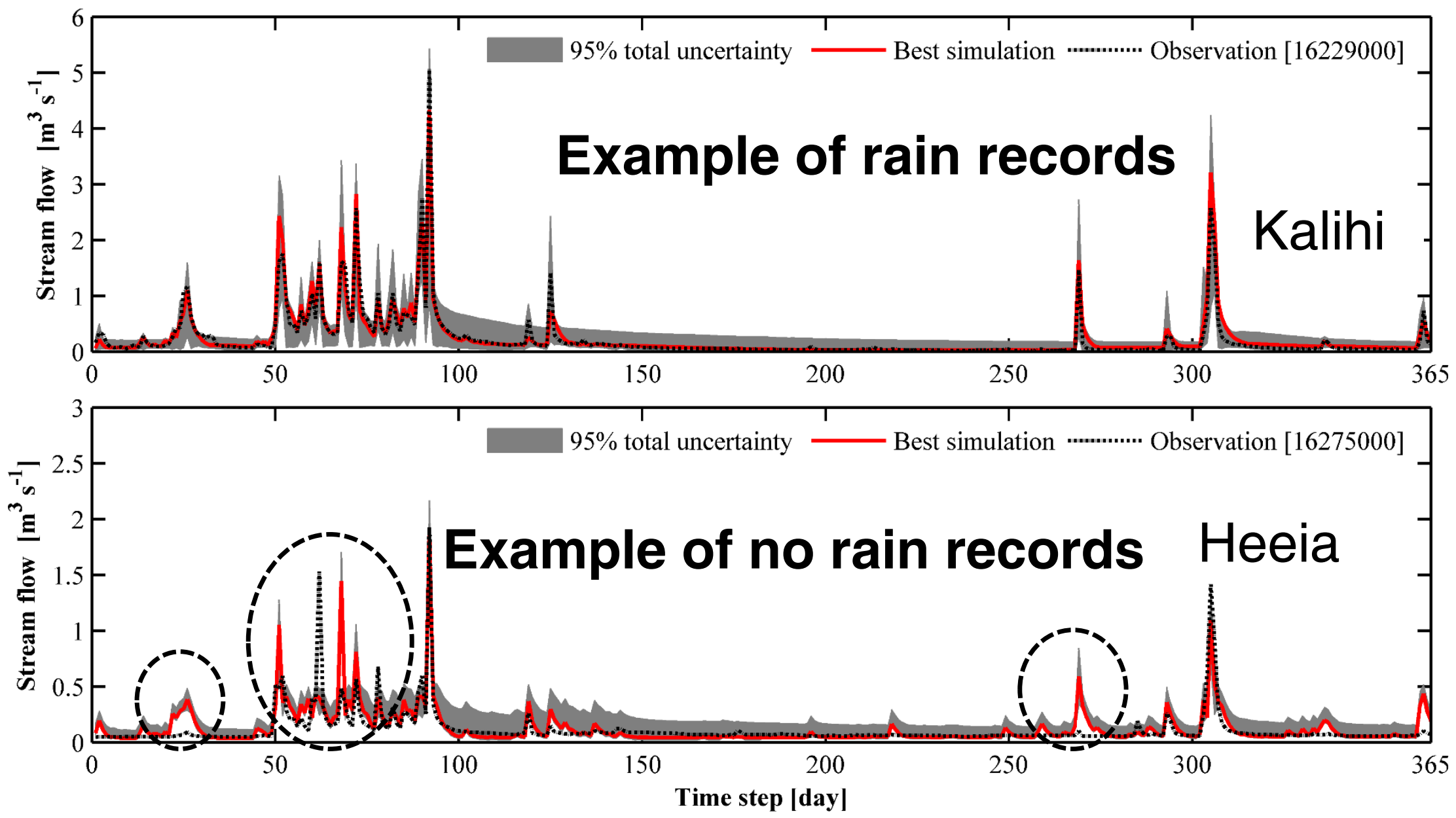

-Rain records: $P$-factor $=0.83$ to 0.93 ; $r$-factor $=0.72$ to 0.84 -Without rain records: $p$-factor $=0.41$ to 0.76 ; $r$-factor $=0.89$ to 1.18 
Temporal variability of observed streamflow sufficiently

captured for watershed with rainfall data
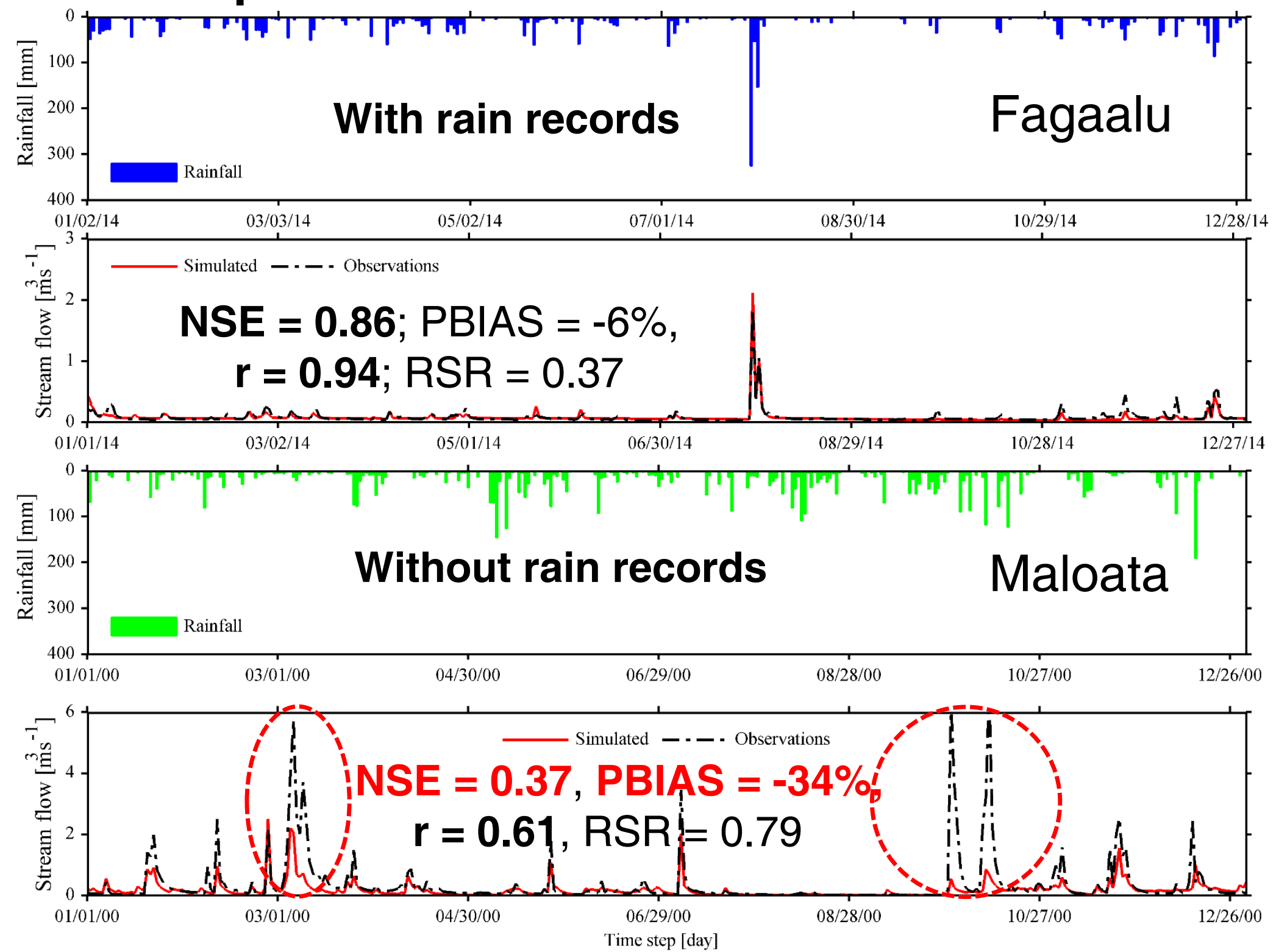

-Peak flows missed for Maloata watershed, low NSE 


\section{$95 \%$ prediction uncertainty did not sufficiently bracket observations for ungauged watersheds}
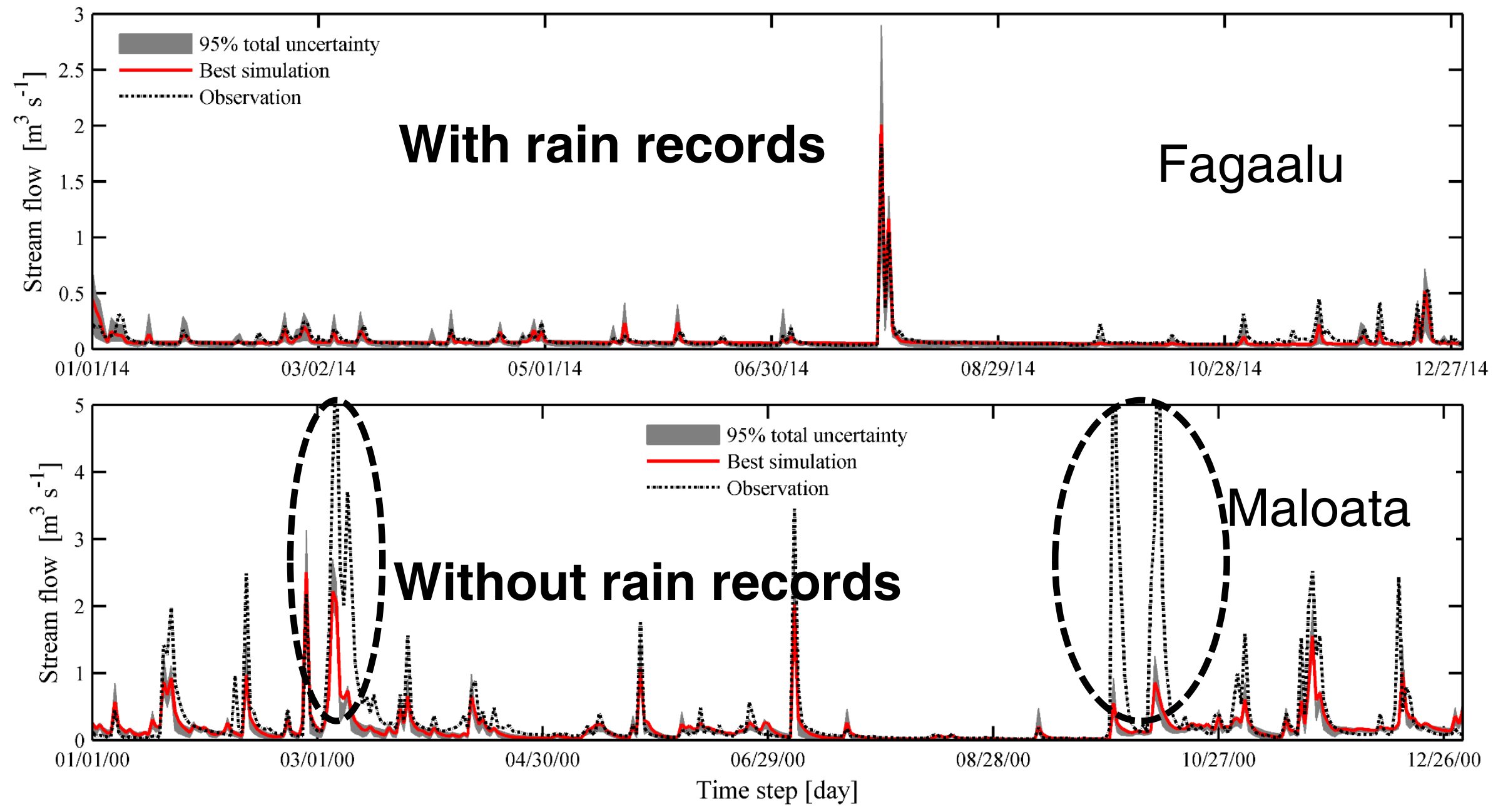

-P-factor, is $\mathbf{0 . 8 7}$ for Fagaalu, but only $\mathbf{0 . 3 8}$ for Maloata watershed -Most of the observations brackets when rainfall data within watershed is used, but results reasonably acceptable 


\section{Multiple rain-gauges improve model performance}
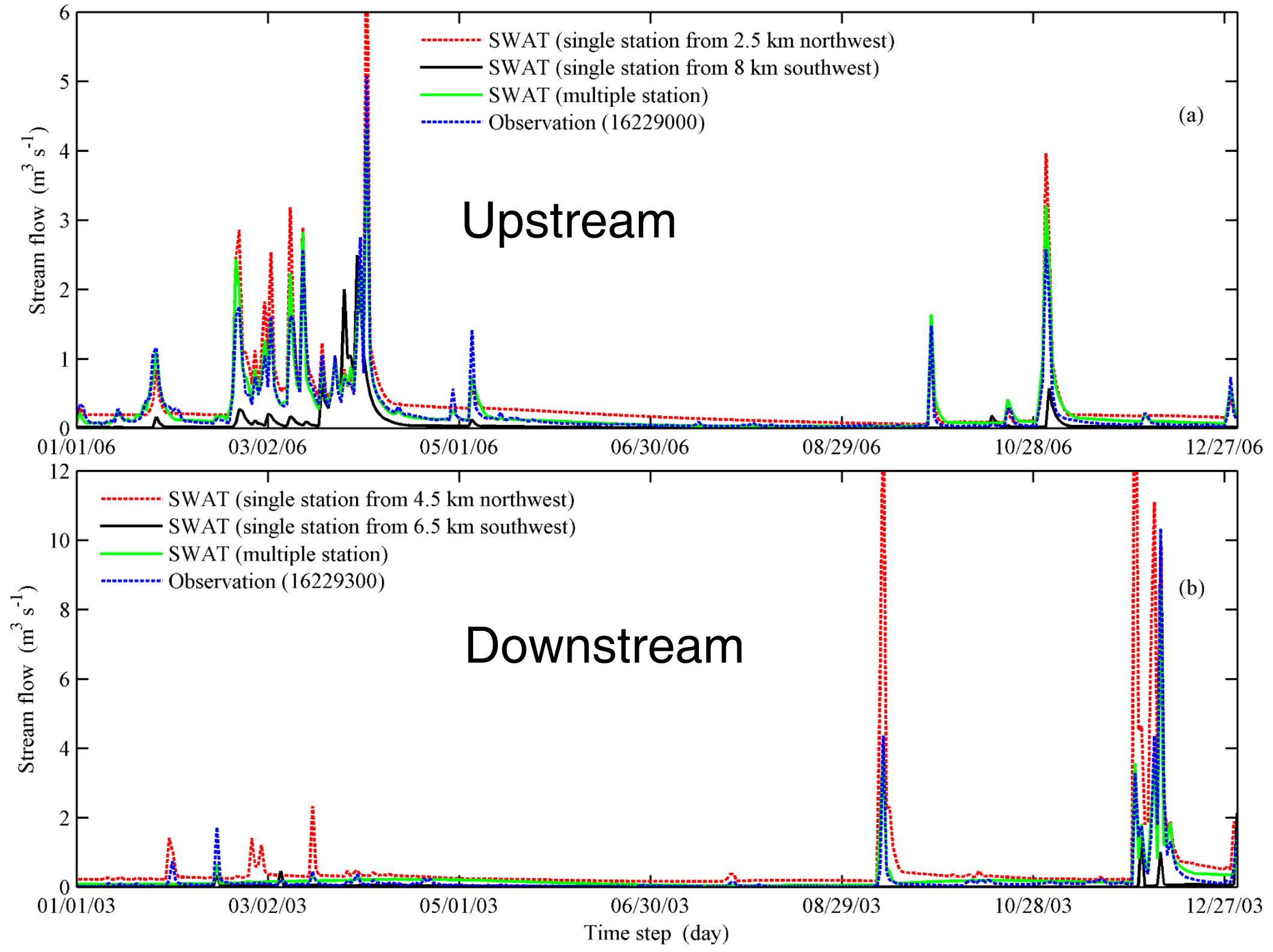

- Use of multiple rain gauging stations well represents hydrographs. 


\section{The Nuuanu area annual water budget}

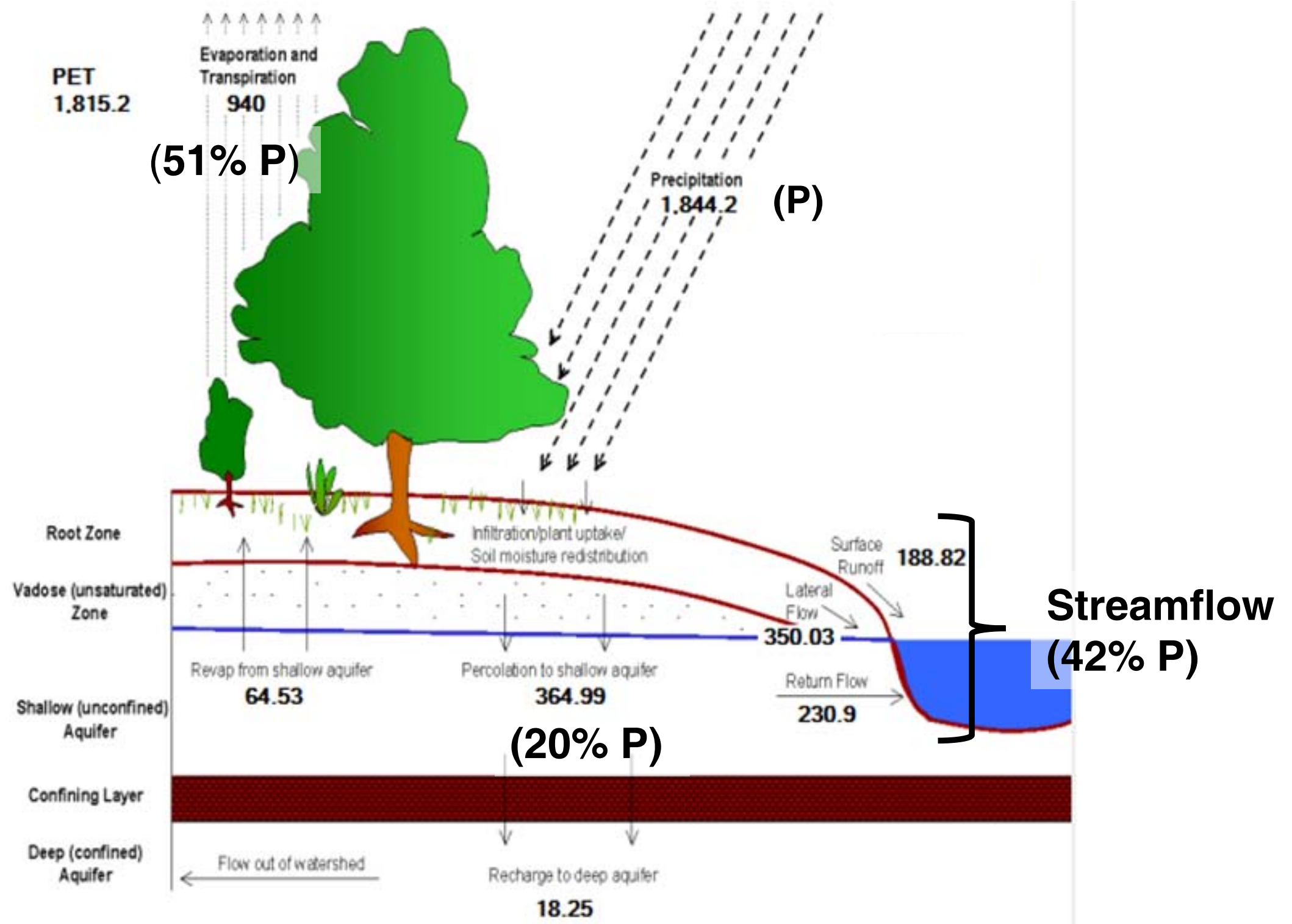

All Units mm

-ET and recharge consistent with previous studies 


\section{The Fagaalu annual water budget}

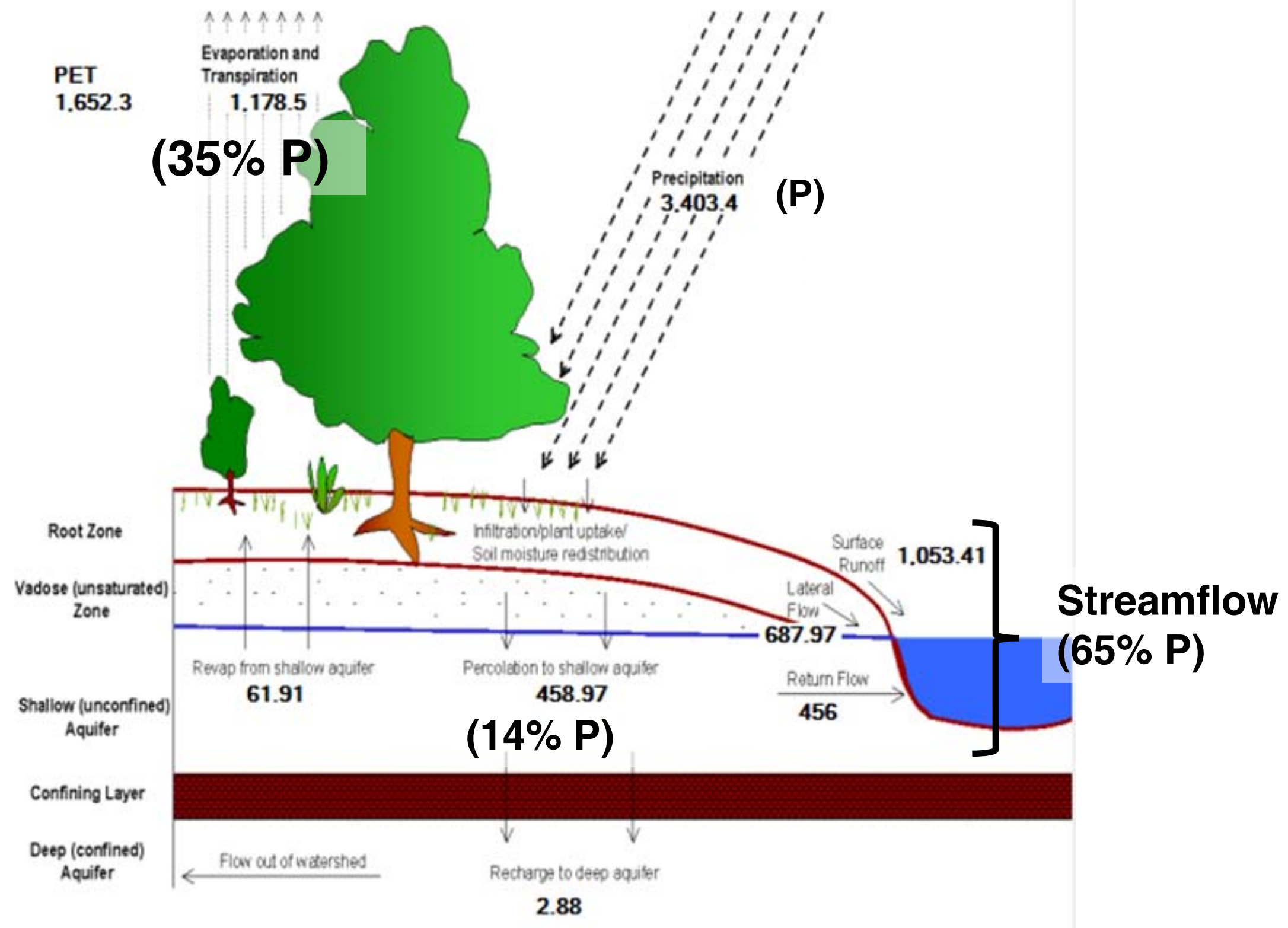

All Units mm

-ET inline with Izuka et al, 2007 Tafuna-Leone Plain 


\section{Conclusions}

-SWAT applicability tested for rain gauged and ungauged watersheds;

- Use of rain records within watershed improved model performance by capturing local climate spatial variability;

-SWAT performed less for watersheds without rain records, but results were reasonably acceptable;

-With methods to resolve data scarcity issues and careful statistical evaluation criteria, data from neighboring areas can be used for watersheds without rain records. 


\section{Acknowledgements to:}
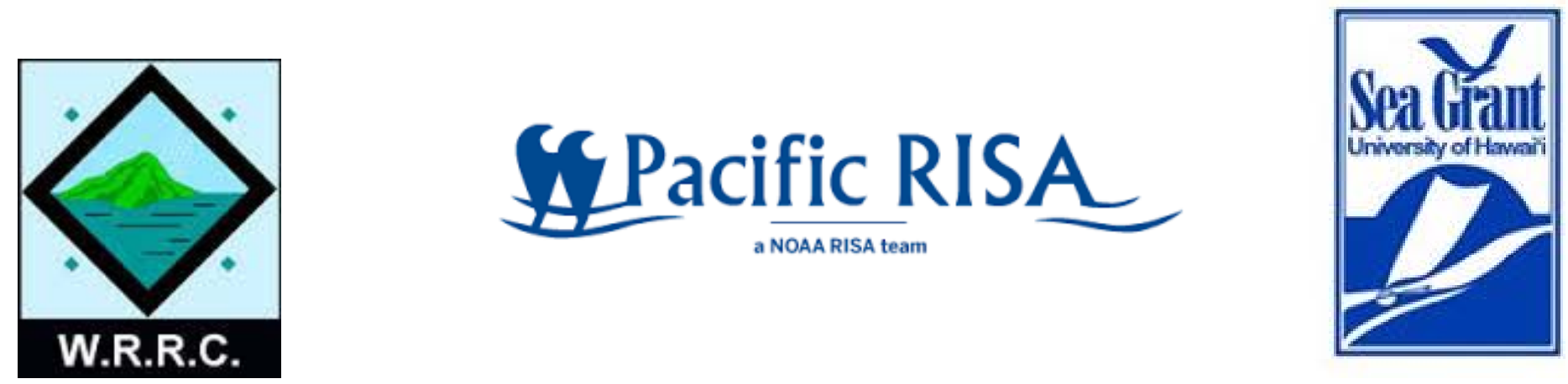

Boand of Wotor Bupply

KĀKO`O ‘ŌIWI 